\title{
The Function of the Spleen.
}

THE number of functions attributed to any organ is often a direct measure of our ignorance as to its real status in the animal economy. The spleen has suffered much from a multiplicity of theories as to its functions, but only two appear to be generally accepted; in fœtal life it acts as one of the sources of the cells of the blood, whilst in the adult these cells, especially the red cells, are here broken down and destroyed when they become worn out. It appears from recent work by Prof. J. Barcroft and his collaborators, an account of which is given in the Lancet of February I4, that a further extremely important function must be attributed to this organ; in their opinion it acts as a storehouse for the red cells of the blood, a number of which may be kept there ready to be brought back into the circulation at a time of emergency.

These workers were first led to a study of this question by finding that when the blood volume increases on exposure of the body to a high external temperature, the increase is not entirely due to the addition of fluid alone to the circulating blood, but that at the same time the total hæmoglobin circulating in the blood increases also. There is no evidence of an increase in the number of newly formed red cells until after a few days have elapsed, so that the additional hæmoglobin-and corpuscles containing it -must have come from some store, and not be due to a new formation, at any rate at first; moreover, the rate of appearance of this hæmoglobin is too great for it to be due simply to new formation. In their search for this store of red cells the investigators naturally thought of the spleen; if their supposition was to be considered correct, they must be able to answer in the affirmative these two questions: Is there, in fact, a store of red cells in the spleen, which are usually outside the general circulatory stream ? Is the number of these stored cells sufficient to account for the increase in circulating hæmoglobin observed on exposure to a high external temperature?

The answer to the first question was found by an examination of the effects of breathing small amounts of carbon monoxide upon the blood in the spleen. The experiments were conducted upon a number of different animals, and it was conclusively shown that there was a lag in the taking up of this gas by the red cells in the spleen as compared with those in the general circulation. In fact, if the percentage of gas breathed was sufficiently small, the hæmoglobin in the spleen might still contain none after several hours; on the other hand, when the animal was placed again in ordinary air, the carbon monoxide came off from the blood in the spleen much more slowly than from that in the general circulation. The blood in the spleen is thus outside the circulation, but this statement is only true for an animal at rest; in activity the carbon monoxide penetrates into the organ at once, so that under these conditions the stored blood appears to be in circulation. Further experiments have shown that under conditions where the amount of oxygen in the blood is less than normal, as, for example, after administration of carbon monoxide, the spleen is stimulated to contract by impulses from the central nervous system, the amount of blood forced out depending partly on the degree of such stimulation. Although it has been known for a long time that the spleen can undergo variations in size from the contraction of the unstriped muscle fibres it contains, the reason for this contractility is thus only now becoming apparent. Furthermore, bearing this capacity of the spleen to vary its size in mind, it may be asked: What is the real size of this organ? And are its variations in size of sufficient amplitude to account for the increase in circulating hæmoglobin with increase in the blood volume?

Little information on these questions can be derived from a study of the size of the spleen in the dead animal, since we have no means of knowing whether the muscle in it has maintained its in vivo length. We should expect to find, in fact, that it has contractèd, so that the organ will be smaller than in life; but how much smaller we cannot judge. It is clear that the organ must be examined in the living animal and without subjecting it to any exposure which might stimulate its smooth muscle fibres. Since it is not opaque to the X-rays, Barcroft and his co-workers fastened small metal clips to its edges in the living animal under an anæsthetic. After the wound had healed, X-ray photographs were taken in two planes, and from these it was easy to reconstruct in a model the size and shape of the organ under different conditions; the approximate weight was also ascertainable, after the animal had been killed, by comparing its size and weight after death with the size found during life. It was found that the weight during life might be two to six times that observed after death; in fact, no less than one-sixth of the total blood volume, or one-third of the red cells, might be contained in the organ during life. A comparison of its size at rest and during exercise suggests that an amount of blood equivalent to about one-quarter of the blood volume may be squeezed out of the organ during activity. The evidence appears conclusive that a large amount of blood may be stored in the spleen, available for emergencies.

Finally, since it is known that in man the spleen may be removed without apparent harm to the individual, Barcroft has inquired whether the absence or not of the organ makes any real difference to the organism. He found that animals without spleens died sooner than controls on exposure to an atmosphere containing carbon monoxide. Thus an individual with a spleen will be able to meet an emergency with more success than one from whom the organ has been removed.

\section{Science in Russia.}

$\mathrm{IT}^{\mathrm{T}}$ is gratifying to learn from a correspondent that, throughout the troubled period of the past few years, the splendid premises and wonderful collections of the famous Zoological Museum of the Academy of Sciences in Leningrad have scarcely felt the breath of war, famine, pestilence, and revolution which has passed over them. When the English traveller walks in, and is greeted by the famous young mammoth from Siberia, preserved like a recently killed specimen, and sees the rich collections illustrating the fauna of the vast steppes and deserts of Russian Asia, he feels that he is entering into a new world.

During the cold winter of I9I9-I920, when fuel was unobtainable, it was impossible to heat the Museum premises, but the staff suffered more than the collections. Little or no looting was done during the disorders, except that the director had some difficulty in preventing the valuable collection of skins from being taken to be used as furs by the shivering population. Far more damage was done 